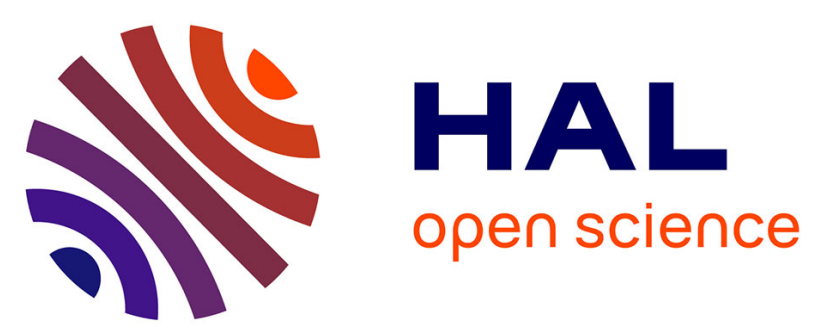

\title{
Functionalization control of porous silicon optical structures using reflectance spectra modeling for biosensing applications
}

Nathalie Lorrain, Mohamed Hiraoui, Mohammed Guendouz, Lazhar Haji

\section{- To cite this version:}

Nathalie Lorrain, Mohamed Hiraoui, Mohammed Guendouz, Lazhar Haji. Functionalization control of porous silicon optical structures using reflectance spectra modeling for biosensing applications. Materials Science and Engineering: B, 2011, 176 (14), pp.1047-1053. 10.1016/j.mseb.2011.05.040 . hal-00804199

\section{HAL Id: hal-00804199 \\ https://hal.science/hal-00804199}

Submitted on 25 Mar 2013

HAL is a multi-disciplinary open access archive for the deposit and dissemination of scientific research documents, whether they are published or not. The documents may come from teaching and research institutions in France or abroad, or from public or private research centers.
L'archive ouverte pluridisciplinaire HAL, est destinée au dépôt et à la diffusion de documents scientifiques de niveau recherche, publiés ou non, émanant des établissements d'enseignement et de recherche français ou étrangers, des laboratoires publics ou privés. 


\title{
Functionalization control of porous silicon optical structures using reflectance spectra modeling for biosensing applications
}

\author{
N. Lorrain ${ }^{1 *}$ M. Hiraoui ${ }^{1,2}$, M. Guendouz ${ }^{1}$ and L. Haji ${ }^{1}$ \\ (1) Université Européenne de Bretagne, CNRS-UMR 6082, BP 80518, ENSSAT 6 rue \\ Kerampont, 22305 Lannion Cedex, France

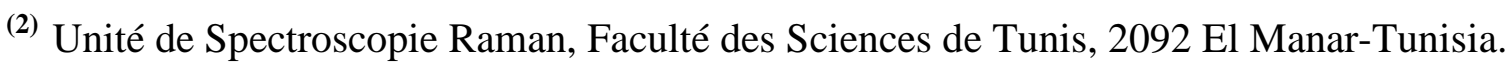 \\ * Corresponding author: nathalie.lorain@univ-rennes1.fr
}

\begin{abstract}
Modeling and experimental reflectance spectra of porous silicon single layers at different steps of functionalization and protein grafting process are adjusted in order to determine the volume fraction of the biomolecules attached to the internal pore surface. This method is applied in order to control the efficiency of the chemical functionalization process of porous silicon single layers. Using results from single porous silicon layer study, theoretical microcavity is simulated at each step of the functionalization process. The calculated reflectance spectrum is in good agreement to the experimental one. Therefore the single layers study can be applied to multilayer structures and can be adapted for other optical structures such as waveguides, interferometers for biosensing applications.
\end{abstract}

\section{Keywords}

Porous silicon; Functionalization; Microcavity; Optical reflectance study; Simulation. 


\section{Introduction}

This last decade, porous silicon (PS) has become an attractive material which is widely used in optical sensing applications for different targets such as gases, enzymes, proteins...due to its large specific sensing area [1-5]. The most common technique used for the PS elaboration is the electrochemical etching in aqueous hydrofluoric acid (HF) [6]. The electrochemical conditions as well as the choice of the type and the resistivity of silicon substrate constitute the key parameters which control the refractive index and the morphology of porous silicon [6]. Indeed, the applied method allows the modulation of refractive index and pore size and enables various optical devices such as waveguides [7], Bragg reflectors and microcavities $[8,9]$ to be elaborated. In such optical structures, the incorporation of species in the pores increases the refractive index of the medium. In particular, a microcavity is very sensitive to refractive index variations. In fact, the attachment of biomolecules is detected by shifts in the resonant wavelength [3].

Moreover, the pore size has to be large to allow efficient infiltration of biomolecules but small enough to avoid light-scattering effects and to offer a large internal specific surface area. Such a large internal PS surface is necessary in order to enable high quality detection of introduced molecules [9-11].

Among many sensing application fields, PS is largely used as a good matrix for biosensors thanks to its biocompatibility and its capacity to immobilize a large number of biomolecules [3]. In freshly etched structures, the internal surface of PS is essentially constituted of $\mathrm{SiH}$, $\mathrm{SiH}_{2}$ and $\mathrm{SiH}_{3}$ groups [12]. This surface is hydrophobic and unstable for a use in aqueous media. In order to stabilize the PS surface, it is oxidized by a heating treatment to obtain Si$\mathrm{OH}, \mathrm{Si}=\mathrm{O}$ and $\mathrm{Si}-\mathrm{O}-\mathrm{Si}$ groups. This oxidation step is followed by a silanization step in order 
to obtain the covalent attachment of reactive groups of silane. Finally, a coupling agent between silane groups and biomolecules is required for the attachment of protein molecules $[13,14]$

In this paper, we focus on the control of PS functionalization for biomolecules detection using reflectometry method. Glutaraldehyde molecule has been used as the coupling agent. Bovine Serum Albumin (BSA) molecule has been used as the test biomolecule. This is one of the most extensively protein studied [15] and is easily linked to Glutaraldehyde molecules by covalent bend with a good stability [16].

We first present microstructural and optical characterizations of PS single layers. Using a model, the spectral reflectance of PS single layers is calculated for two different anodization conditions and is adjusted to the experimental one in order to determine the volume fractions of the different constituents at each step of the functionalization process.

Then, we present the experimental results of a PS microcavity elaborated and functionalized with the same conditions used in the studied single layers. Using the adjusted volume fractions of each constituent obtained from the single layer study, we calculated the theoretical reflectance spectra of the microcavity after each functionalization step and compared them to the experimental ones.

\section{Experimental}

Porous silicon (PS) single layers and a microcavity have been prepared by anodization process using $\mathrm{P}^{+}$(100) silicon substrate with a 4-6 $\mathrm{m} \Omega . \mathrm{cm}^{-1}$ resistivity. The electrolyte was formed by combining hydrofluoric acid (50\%) with ethanol and deionised water (DIW) with the ratio of 1:2:2 respectively. The anodization duration and the current density were controlled by a programmable current source. Two types of PS layers have been studied using anodic current densities of $40 \mathrm{~mA} / \mathrm{cm}^{2}$ ( $\mathrm{H}$ for high) and $30 \mathrm{~mA} / \mathrm{cm}^{2}$ (L for low). These current 
densities have also been used to elaborate a microcavity with an alternation of 12 periods of $\mathrm{H}$ and L layers for Bragg mirrors separated by the active layer $(\mathrm{H})$.

In order to stabilize freshly etched structures and to prepare the PS surface for attachment of biomolecules purposes, PS surfaces have been partially oxidized at $300^{\circ} \mathrm{C}$ for one hour in wet $\mathrm{O}_{2}$. After this thermal treatment, the surface must be activated with silanol groups. Firstly, partially oxidized porous silicon (POPS) samples were immersed in a $2 \%$ (3Aminopropyl) triethoxysilane (APTES, from Sigma-Aldrich) and a hydro alcoholic mixture of DIW and methanol (1:1) solution for 20 minutes at room temperature. Then, samples were removed from the APTES solution and were rinsed in DI water. Finally, samples were dried with $\mathrm{N}_{2}$ and heated at $100^{\circ} \mathrm{C}$ over 10 minutes to evacuate the solvent vapors.

In the second chemical functionalization step (Coupling step), the samples were impregnated in $2.5 \%$ solution of Glutaraldehyde (GL, from Sigma Aldrich) adjusted to $\mathrm{pH} 7$ using $\mathrm{NaOH}$ $\left(0.5\right.$ mol. $\left.^{-1}\right)$ solution for one hour at room temperature. Then the samples were rinsed in DIW in order to remove any excess of GL molecules and dried under $\mathrm{N}_{2}$ flow.

The last step consisted in incubating at room temperature the functionalized samples in a solution of bovine serum albumine (BSA, from Sigma-Aldrich) for 2 days. The BSA solution was prepared by dissolving $15 \mathrm{mg}$ of BSA powder in $5 \mathrm{ml}$ of DIW. After impregnation, the samples were rinsed with DIW and dried under a steady nitrogen gas flow.

The reflectivity measurements have been performed before and after each functionalization process using UV - VIS - PIR spectrometer (Ocean Optics HR 4000). All reflectance spectra were obtained and investigated in the $800-1100 \mathrm{~nm}$ wavelength range at ambiant temperature.

SEM cross sectional observations using HITACHI S-2500 have provided information on the thickness of the layer with a precision of $0.1 \mu \mathrm{m}$. And from SEM surface observations, it was 
possible to estimate pore size distribution using an image analysis tool developed using MATLAB software.

\section{Modeling}

In the present study, the calculations of the refractive index values and reflectance as a function of wavelength were carried out using a MATLAB program. The matrix transfer method [17] has been applied to calculate reflectance spectra of a PS single layer and a PS microcavity after each elaboration and functionalization step. The thickness of each layer is fixed and obtained from the SEM cross section measurements. To obtain the reflectance spectra, the refractive index of the two different layers and their constituents must be defined as a function of $\lambda$. For silicon or silica, the variation of refractive index values for an intrinsic material has been taken into consideration [18]. For APTES, GL and BSA molecules, we have considered constant refractive indexes which are respectively equal to $1.42,1.43$ and 1.445 [19]. In order to determine the refractive index of the studied layers, we have used the Bruggemann model [20] which relates the refractive index $n_{i}$ of the constituent $i$ to its volume fraction $\mathrm{C}_{\mathrm{i}}$ in an effective medium composed of $\mathrm{i}$ constituent:

$$
\sum_{i} C_{i} \frac{n_{i}^{2}-n^{2}}{n_{i}^{2}+2 n^{2}}=0 \quad \text { (1) } \quad \text { with } \quad \sum_{i} C_{i}=1
$$

Where $n_{i}$ and $n$ are the refractive index of the constituent $i$ and the effective medium respectively.

If the $\mathrm{n}_{\mathrm{i}}(\lambda)$ and the $\mathrm{C}_{\mathrm{i}}$ are known for each constituent $i$ in each layer, the refractive index $\mathrm{n}$ of each layer can be then calculated as a function of $\lambda$.

In our case, each layer is constituted by a network of partially oxidized silicon crystallites separated by pores, the surface of which has been covered by APTES, GL and BSA protein molecules (figure 1). We have neglected the volume fraction of the molecules which are 
attached to the top crystallite surface (hatched area in figure 1). Thus, the effective medium is almost composed of silicon, air, silica, APTES, GL and BSA molecules and is delimited by air and silicon substrate.

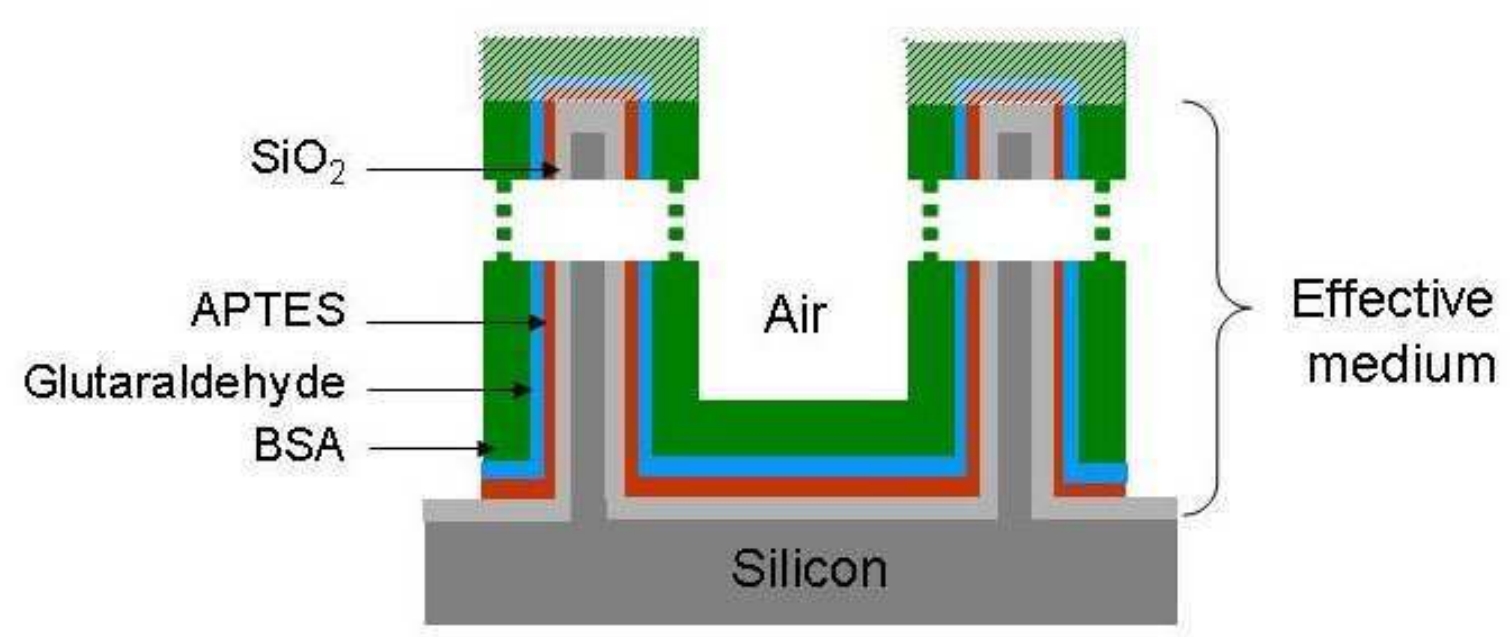

Figure 1: Schematic of a functionalized partially oxidized PS layer. The volume fraction of molecules which is deposited on the top partially oxidized silicon crystallites surface is not taken into consideration in the model of refractive index estimation.

The method of determining the refractive index of PS single layers has been based on the adjustment of the experimental reflectance spectra with the theoretical ones for each elaboration and functionalization step: only one parameter is then unknown which is the volume fraction of the constituent $i$ added at the step $i$. This parameter was initially arbitrarily fixed in order to calculate the refractive index $n$, and then the reflectance $\mathrm{R}$ for each $\lambda$ was deduced. The parameter was then varied in order to adjust the experimental with the calculated reflectance spectra. The volume fraction of the constituent $i$ was equal to the adjusted parameter. 
The method used for obtaining an estimation of the refractive index and applied at each step is detailed as follows.

- Step 1, as-prepared PS layer:

After the PS formation step, the constituents of the layer delimited by air and silicon substrate are the silicon (volume fraction $\mathrm{C}_{\mathrm{Si}_{-} 1}$ ) and air (volume fraction $\mathrm{C}_{\text {air_l }}$ : porosity). By fixing an initial value for $\mathrm{C}_{\text {air_1 }}$, the refractive index $\mathrm{n}$ of the effective medium and therefore a theoretical reflectance spectrum can be calculated and compared to the experimental one. Then, the $\mathrm{C}_{\text {air_1 }}$ is adjusted in order to fit the experimental reflectance spectrum with the calculated one (Figure 2).

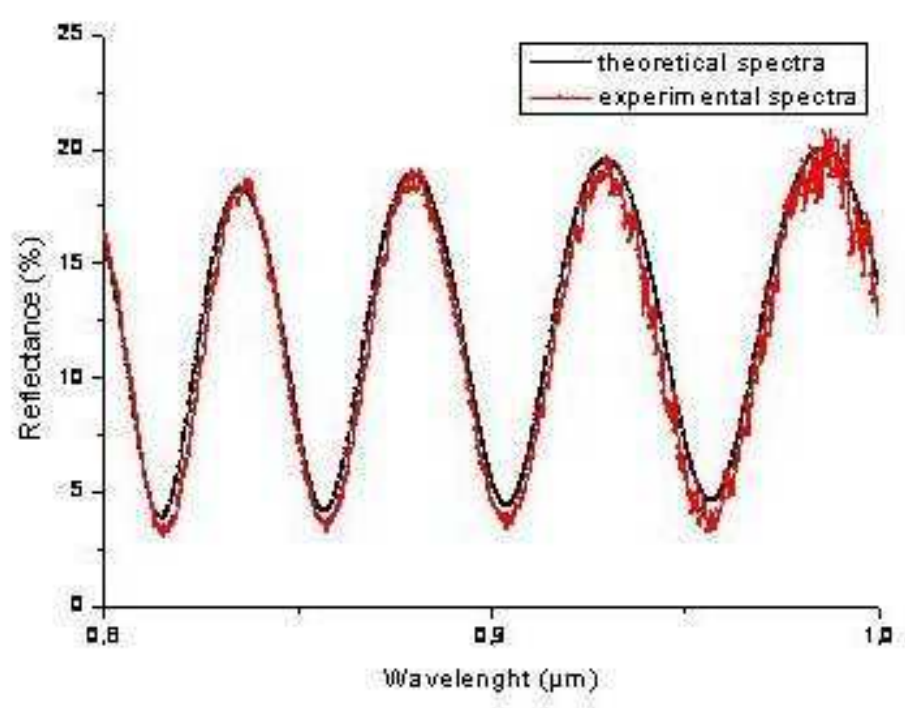

Figure 2: Example of adjustment of the experimental and calculated spectra for the as prepared porous silicon layer.

- Step 2, after partial oxidation:

By taking into consideration $\mathrm{C}_{\mathrm{Si}_{-} \mathrm{O}}$, the silicon volume fraction which is oxidized and the volume expansion of silicon, the volume fraction of silica is equal to: 


$$
C_{\mathrm{SiO}_{2_{-} 2}}=2.27 C_{\mathrm{Si}_{-} \mathrm{o}}[21,22]
$$

Consequently, porosity decreases and is equal to :

$$
C_{a i r_{-} 2}=C_{a i r_{-} 1}-1.27 C_{S i_{-} o}
$$

The new volume fraction of silicon is given by the following relation:

$$
C_{S i_{-} 2}=C_{S i_{-} 1}-C_{S i_{-} o}
$$

The unknown quantity is $\mathrm{C}_{\mathrm{Si}_{-} \mathrm{O}}$ and this value is determined by the adjustment of theoretical and experimental reflectance spectra.

- After silanization (step 3), coupling (step 4) and grafting (step 5):

The silica and silicon volume fractions remain constant. We consider $\mathrm{C}_{\mathrm{APTES}}, \mathrm{C}_{\mathrm{GL}}$ and $\mathrm{C}_{\mathrm{BSA}}$ the volume fractions of APTES, GL and BSA molecules respectively. These molecules are attached to the partially oxidized silicon crystallite internal surface. The unknown volume fractions of $\mathrm{C}_{\mathrm{APTES}}, \mathrm{C}_{\mathrm{GL}}$ and $\mathrm{C}_{\mathrm{BSA}}$ are also deduced from the adjustment of the theoretical with experimental reflectance spectra. The residual porosity after silanization, coupling and grafting steps $\left(\mathrm{C}_{\text {air_5 }}\right)$ is then equal to:

$$
C_{a i r_{-} 5}=C_{a i r_{-} 2}-C_{A P T E S}-C_{G L}-C_{B S A}
$$

Thus, adopting this method, we can deduce the different volume fractions for each constituent of each PS single layer and also its refractive index at each step of the functionalization process. 


\section{Results and discussion}

\subsection{PS single layers}

In order to calculate reflectance of PS single layers, their thickness must be defined. SEM cross sectional observations of PS single layers were performed just after elaboration and partial oxidation steps (Figure 3).

(a)
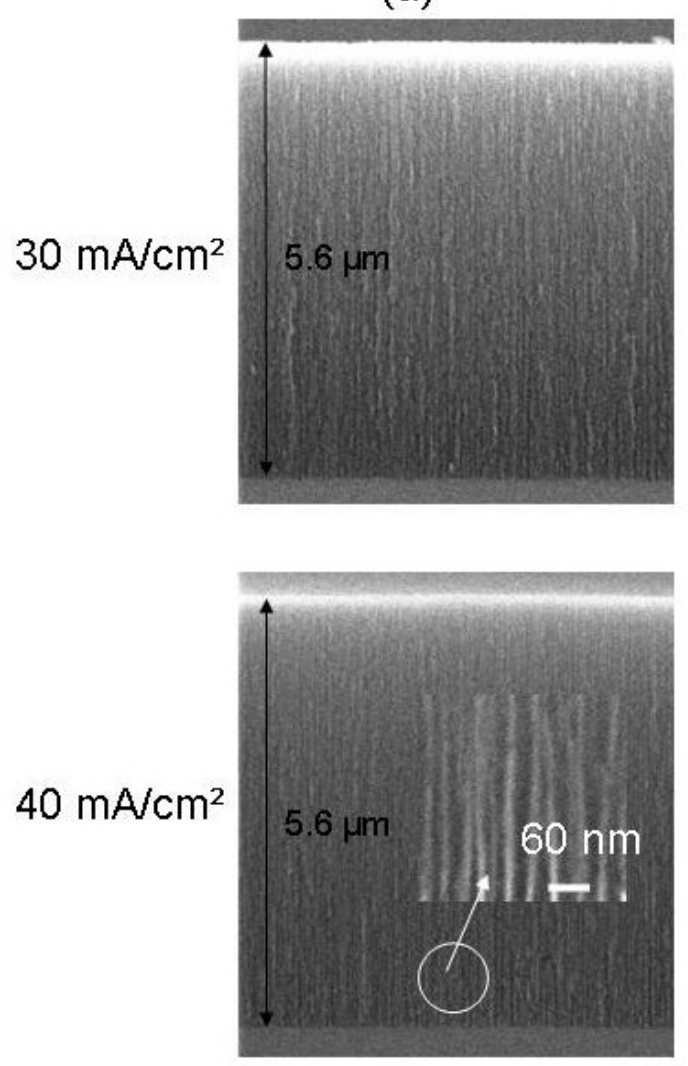

(b)
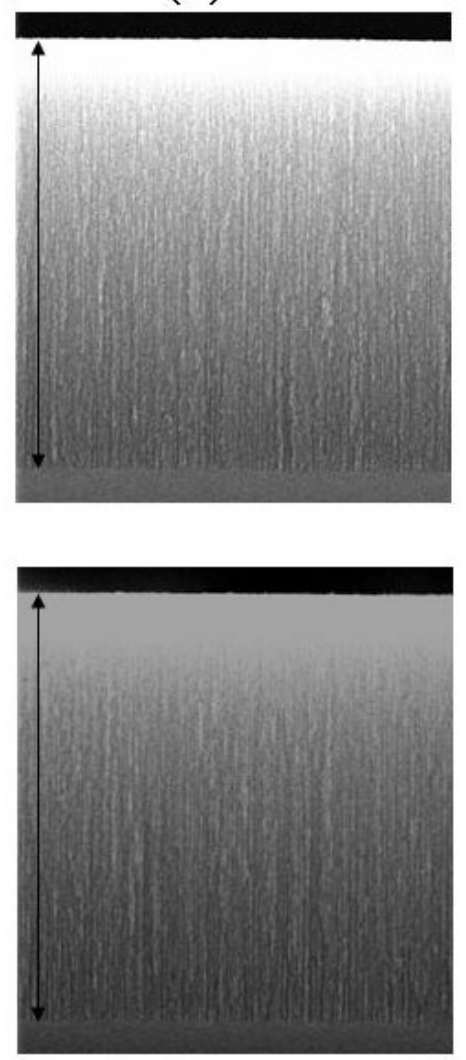

Figure 3: Cross sectional SEM images of (a) as prepared PS layer and (b) after partial oxidation step for the studied anodization current densities of $30 \mathrm{~mA} / \mathrm{cm}^{2}$ and $40 \mathrm{~mA} / \mathrm{cm}^{2}$ respectively.

The increase in thickness due to silicon volume expansion after partial oxidation was found to be below the estimated error measurement which is about $0.1 \mu \mathrm{m}$. So the thickness of the PS layer can be considered to remain constant after the oxidation step. Moreover, from the 
single layer measured thickness, we have estimated the etching anodization rate which is about $17 \mathrm{~nm} / \mathrm{s}$ and $21 \mathrm{~nm} / \mathrm{s}$ respectively for the $\mathrm{L}$ and $\mathrm{H}$ current density. SEM observations at a higher magnification of the PS cross section have shown columnar pores (figure 3.a). This morphology of pores which is observed for the two chosen current densities is suitable for easy molecule infiltration.

The pore diameter and porosity are crucial for molecule infiltration. Porosity must be high and pores must be small enough to preserve a high internal surface for sensitive molecule detection. Surface SEM observations and image analyses of PS samples after partial oxidation have been used in order to estimate the mean pore diameter $\mathrm{D}$ which is about $34 \mathrm{~nm}$ and $43 \mathrm{~nm}$ respectively for the $\mathrm{L}$ and the $\mathrm{H}$ layer conditions (figure 4.a).
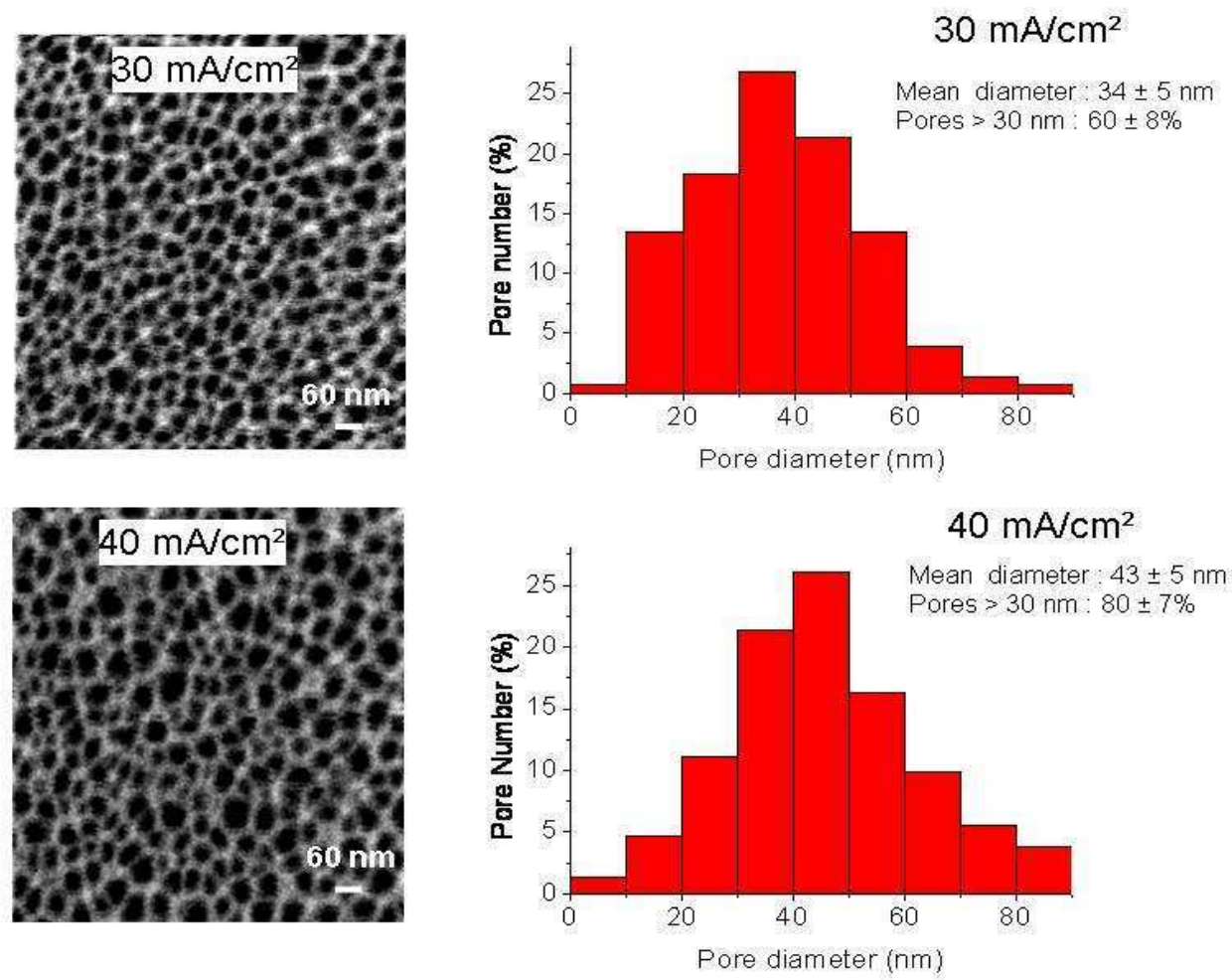

(a)

(b)

Figure 4: (a) Surface SEM images and (b) histograms of pore diameters for the studied anodization current densities of $30 \mathrm{~mA} / \mathrm{cm}^{2}$ and $40 \mathrm{~mA} / \mathrm{cm}^{2}$ after the partial oxidation step. 
These pore sizes are large enough for APTES and GL molecule infiltration since the molecule sizes are respectively $0.8 \mathrm{~nm}[23]$ and $0.7 \mathrm{~nm}[24]$. As for the test molecule (BSA), according to the pore size histograms (figure 4.b), very few pores have a dimension below the largest size of the molecule which is $14 \mathrm{~nm}$ [25]. According to figure 4.b, the percentage of pores with a size greater than $30 \mathrm{~nm}$ (which is twice the size of the molecule) is about $60 \%$ and $80 \%$ respectively for $\mathrm{L}$ and $\mathrm{H}$ current densities conditions. So this protein molecule can easily penetrate into the pores during the grafting process.

In order to determine the refractive index of PS single layers after each step of functionalization, reflectance spectra have been measured and the volume fraction of each constituent has been deduced by adjustment with the calculated spectra. For calculation purposes, the thickness of each PS layer has been considered to be constant during the process of functionalization according to cross sectional SEM observations.

In table 1, we report the different volume fractions and the refractive indexes deduced from the adjustment of the experimental with theoretical reflectance spectra of PS single layers after each step for the $\mathrm{L}$ and $\mathrm{H}$ current densities. As far as the initial porosity of the sample is needed, we have performed gravimetric analyses and the results of these measurements are in good agreement with the porosities deduced from optical method.

From the porosity value $\left(\mathrm{C}_{\mathrm{Air}_{2} 2}\right)$ and mean pore diameter $(\mathrm{D})$ previously determined, we can estimate the specific surface per volume unit by the following relation:

$$
S_{p}=\frac{4000 \cdot C_{\text {Air_-2 }_{-}}}{D(n m)} \mathrm{m}^{2} / \mathrm{cm}^{3}[26]
$$

After the oxidation step, $\mathrm{S}_{\mathrm{p}}=81 \mathrm{~m}^{2} / \mathrm{cm}^{3}$ and $68 \mathrm{~m}^{2} / \mathrm{cm}^{3}$ respectively for $\mathrm{L}$ and $\mathrm{H}$ current density conditions. 


\begin{tabular}{|c|c|c|}
\hline Steps & $30 \mathrm{~mA} / \mathrm{cm}^{2}$ & $40 \mathrm{~mA} / \mathrm{cm}^{2}$ \\
\hline \multirow[t]{2}{*}{ (1) As prepared } & $\mathrm{C}_{\text {air_1 } 1}=76 \pm 1 \%$ & $\mathrm{C}_{\text {air_1 } 1}=83 \pm 1 \%$ \\
\hline & $\mathrm{n}_{800}=1.420 \pm 0.025$ & $\mathrm{n}_{800}=1.272 \pm 0.021$ \\
\hline \multirow[t]{4}{*}{ (2) After oxidation } & $\mathrm{C}_{\mathrm{Si}_{-} 2}=17.8 \pm 1.4 \%$ & $\mathrm{C}_{\mathrm{Si}_{-} 2}=9.4 \pm 1.8 \%$ \\
\hline & $\mathrm{C}_{\mathrm{SiO} 2 \_2_{2}}=13.02 \pm 0.78 \%$ & $\mathrm{C}_{\mathrm{SiO} 2 \_2}=17.2 \pm 1.7 \%$ \\
\hline & $\mathrm{C}_{\text {Air_2 }}=69.22 \pm 0.58 \%$ & $\mathrm{C}_{\text {Air_2 }}=73.28 \pm 0.06 \%$ \\
\hline & $\mathrm{n}_{800}=1.364 \pm 0.026$ & $\mathrm{n}_{800}=1.220 \pm 0.023$ \\
\hline \multirow[t]{2}{*}{ (3) After silanization } & $\mathrm{C}_{\text {APTES }}=8.12 \pm 0.13 \%$ & $\mathrm{C}_{\mathrm{APTES}}=7.75 \pm 0.25 \%$ \\
\hline & $\mathrm{n}_{800}=1.408 \pm 0.026$ & $\mathrm{n}_{800}=1.259 \pm 0.025$ \\
\hline \multirow[t]{2}{*}{ (4) After coupling } & $\mathrm{C}_{\mathrm{GL}}=8.50 \pm 0.25 \%$ & $\mathrm{C}_{\mathrm{GL}}=7.25 \pm 0.25 \%$ \\
\hline & $\mathrm{n}_{800}=1.456 \pm 0.029$ & $\mathrm{n}_{800}=1.295 \pm 0.025$ \\
\hline \multirow[t]{3}{*}{ (5) After grafting } & $\mathrm{C}_{\mathrm{BSA}}=3.88 \pm 0.38 \%$ & $\mathrm{C}_{\mathrm{BSA}}=21.87 \pm 0.34 \%$ \\
\hline & $\mathrm{C}_{\text {Air_5 }}=48.72 \pm 0.82 \%$ & $\mathrm{C}_{\text {Air_5 }}=36.79 \pm 0.82 \%$ \\
\hline & $\mathrm{n}_{800}=1.478 \pm 0.029$ & $\mathrm{n}_{800}=1.407 \pm 0.027$ \\
\hline
\end{tabular}

Table 1: Volume fraction of the different constituents in PS single layers after each step of elaboration, functionalization and grafting processes. The precision of the results has been deduced from the adjustment of experimental and theoretical spectra by considering the minimum and the maximum thickness for each PS layer.

Analyzing the silanization and coupling step results in table 1, we can notice that the volume fractions of APTES and GL molecules are slightly lower for the $\mathrm{H}$ than for the L conditions.

This result can be explained by the specific surface which is also slightly lower in this condition. On the contrary, for the protein grafting step, even though there is a higher internal pore surface, the volume fraction of BSA is significantly lower for $\mathrm{L}$ than for $\mathrm{H}$ condition. We attribute this result to the pore diameters which must be too small for infiltration of BSA molecules. 
Figure 5 shows the evolution of the refractive index of the PS layers as a function of wavelength at different biding steps which has been deduced from volume fractions obtained.

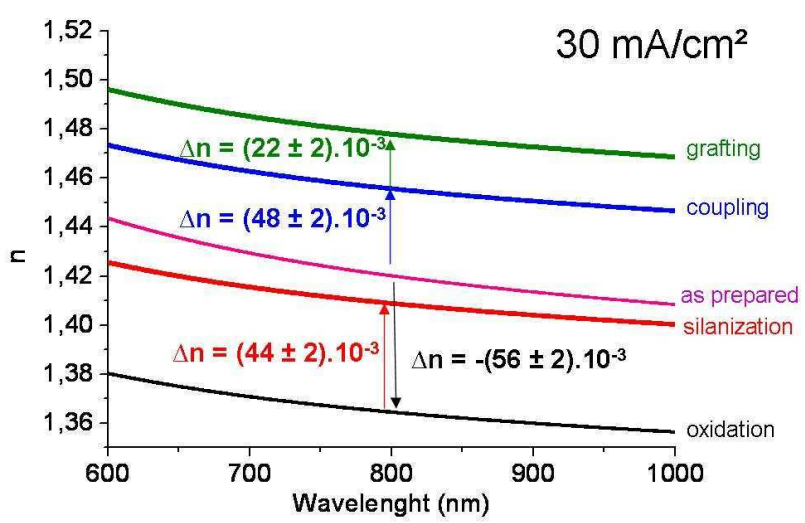

(a)

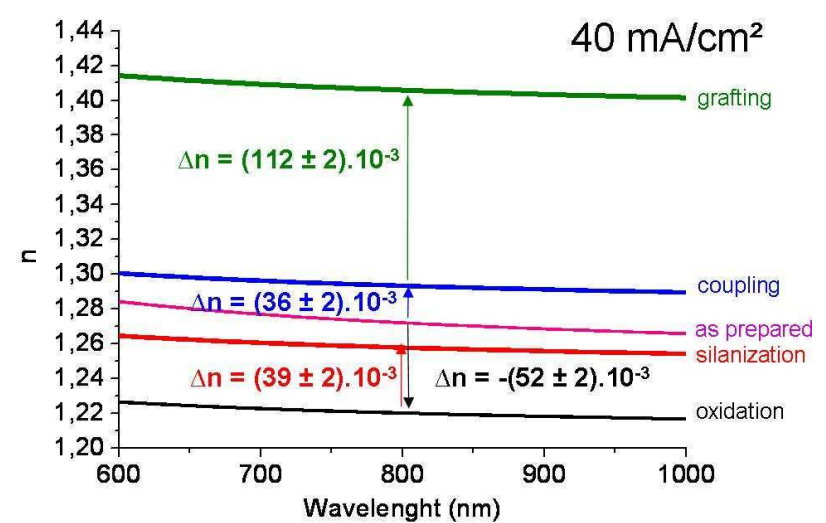

(b)

Figure 5 : Refractive index (n) evolution versus wavelength for each step of functionalization and refractive index variation $(\Delta \mathrm{n})$ between two subsequent steps at $\lambda=800 \mathrm{~nm}$ for the two studied anodization current densities : $30 \mathrm{~mA} / \mathrm{cm}^{2}$ (a) et $40 \mathrm{~mA} / \mathrm{cm}^{2}$ (b) . Values are deduced using the mean thickness of each PS layer.

The variation in the refractive index $(\Delta \mathrm{n})$ at $\lambda=800 \mathrm{~nm}$ is also indicated. After oxidation, $\Delta \mathrm{n}$ is negative because the silica index is lower than the silicon index. However, after functionalization steps, $\Delta \mathrm{n}$ is positive due to the replacement of the air in the pores with added molecules. The obtained values are correlated with the volume fraction of molecules previously presented: $\Delta \mathrm{n}$ values are higher for the L current density condition except for the protein grafting step because of a lower infiltration of BSA molecules.

\subsection{Porous silicon microcavity}

PS microcavity has been prepared by applying a periodic current density pulse train of 40 $\mathrm{mA} / \mathrm{cm}^{2}$ and $30 \mathrm{~mA} / \mathrm{cm}^{2}$ with an alternation of $\mathrm{N}_{\mathrm{A}}=\mathrm{N}_{\mathrm{B}}=12$ for the mirrors $\mathrm{A}$ and $\mathrm{B}$ defined in figure 6a. A resonant wavelength of $800 \mathrm{~nm}$ was fixed. The theoretical thickness and its 
precision for each layer of the microcavity have been deduced from the refractive index and its variation previously calculated at this wavelength: $\mathrm{e}_{\mathrm{H}}=162.8 \pm 2.6 \mathrm{~nm}$ and $\mathrm{e}_{\mathrm{L}}=145.8 \pm 2.0 \mathrm{~nm}$ respectively for $40 \mathrm{~mA} / \mathrm{cm}^{2}(\mathrm{H})$ and $30(\mathrm{~L}) \mathrm{mA} / \mathrm{cm}^{2}$. Then from the anodization rates previously estimated we have deduced the anodization times for the $\mathrm{H}$ and $\mathrm{L}$ current densities (figure 6.a).

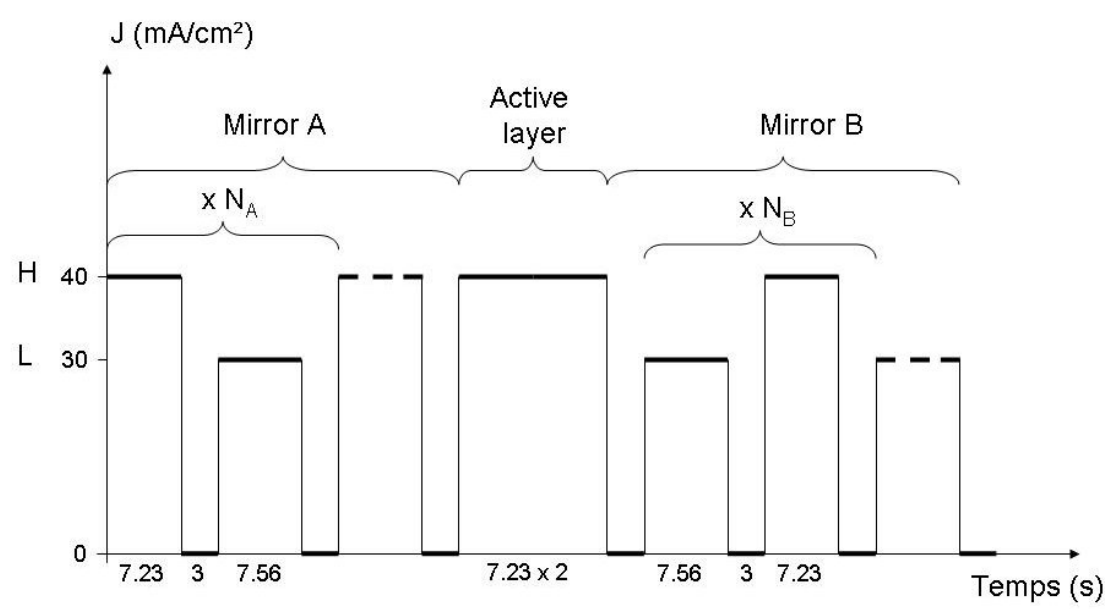

(a)

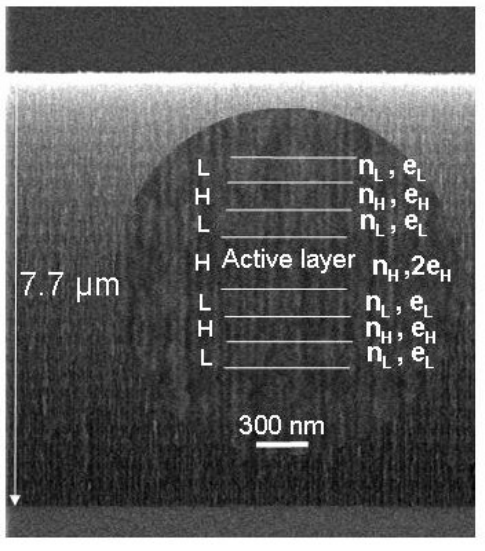

(b)

Figure 6: (a) Schematic anodization current density variation used for microcavity elaboration $\left(\mathrm{N}_{\mathrm{A}}\right.$ $=\mathrm{N}_{\mathrm{B}}=12$ ); (b) Cross section SEM image of the as prepared microcavity.

Figure 6.b shows a cross sectional SEM micrograph of the as-prepared microcavity. The estimated thickness is in the same order of magnitude as the aimed calculated thickness. Reflectance spectrum of the as-prepared microcavity shows a resonant wavelength of 827.3 $\mathrm{nm}$ which is slightly different from the fixed one $(800 \mathrm{~nm})$. Cross sectional SEM observations of the overall microcavity before and after different steps have not revealed any thickness variation. So, for the reflectance calculations, we considered that the thickness of each layer does not vary after each step. 
The as-prepared microcavity was functionalized in the same conditions as the single layer ones. The reflectance measurements of the microcavity was obtained after each step, being careful to take measurements in the same location (center part) (figures 7.a and 8.a).

From the refractive index values previously determined for the studied PS single layers, we calculated microcavity reflectance at each step of the process. In order to estimate the precision of the resonant wavelength, we have simulated two microcavities using the minimal or maximal refractive index previously estimated for the $\mathrm{H}$ and L layers. In every case, we have considered that molecules were completely infiltrated into the overall thickness of the microcavity.

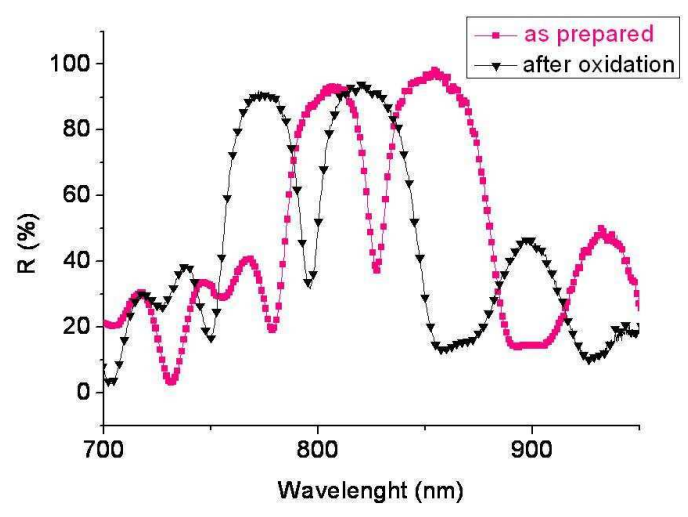

(a)

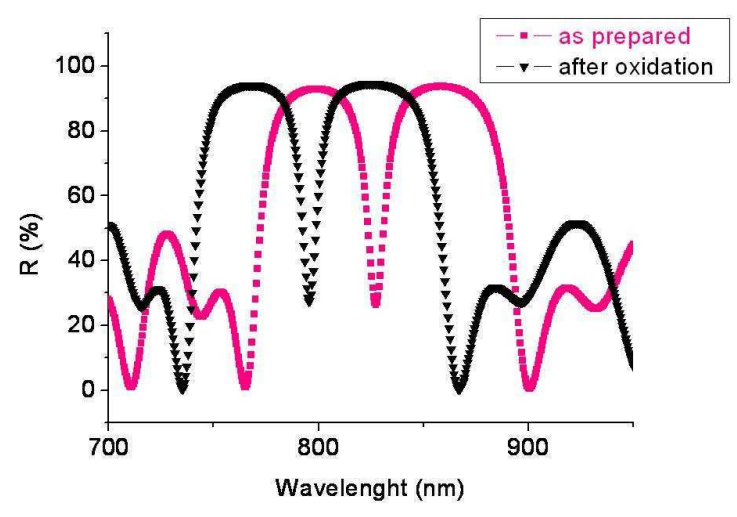

(b)

Figure 7: Reflectance spectra for as prepared and after partial oxidation of PS microcavity; a) experimental; b) theoretical with: $\mathrm{e}_{\mathrm{H}}=165.4 \mathrm{~nm} \mathrm{e}_{\mathrm{L}}=145.8 \mathrm{~nm}$. 


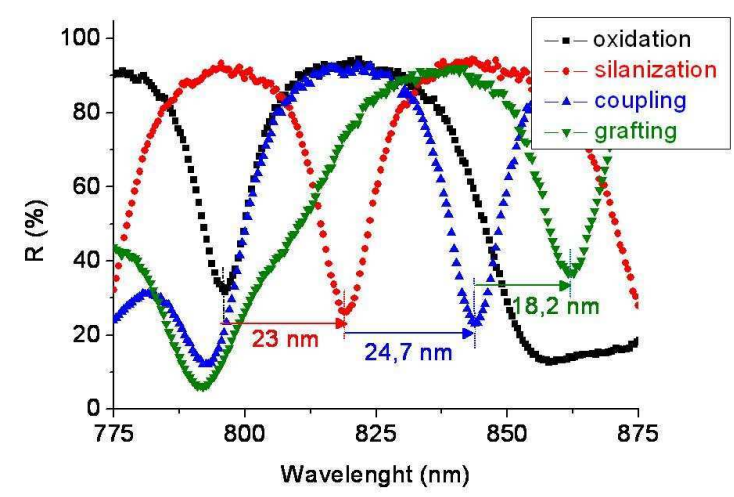

(a)

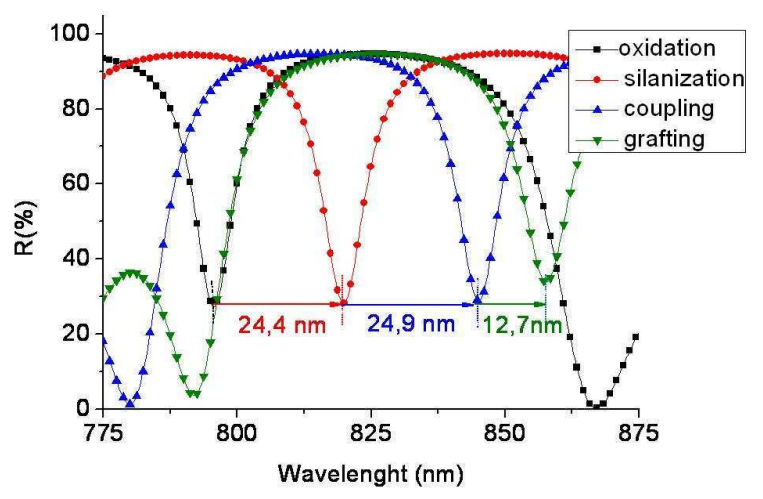

(b)

Figure 8: Reflectance spectra of POPS microcavity after oxidation, silanization, coupling and grafting steps: a) experimental; b) theoretical with $\mathrm{e}_{\mathrm{H}}=165.4 \mathrm{~nm} \mathrm{e}_{\mathrm{L}}=145.8 \mathrm{~nm}$.

For the grafting step, the PS single layer study has revealed a low BSA infiltration for the layer $\mathrm{L}$ which was attributed to small pore diameters. Constituting the limiting condition for BSA infiltration in the microcavity, we used the values obtained in the L conditions for the simulation of the microcavity after the grafting step. The different parameters for microcavity simulations are indicated in table 2.

The spectra are presented in figure 7.b (before and after the oxidation step) and in figure 8.b (from oxidation to grafting steps) considering the mean thickness of each PS layer. The shift of the resonant wavelength of the microcavity, which is the consequence of the index refraction variation of the layers between each step of the process, is noted after oxidation and each functionalization step.

The comparison between the experimental and theoretical microcavity reflectances before and after oxidation (figure 7) well shows very good agreement between calculated and experimental measurement wavelength shifts: $\Delta \lambda_{\text {th }}=-32.4 \pm 1.4 \mathrm{~nm}$ compared to 
$\Delta \lambda_{\exp }=-31.3 \mathrm{~nm}$. Therefore, the volume fraction of air, $\mathrm{Si}$ and $\mathrm{Si}_{2}$ determined by reflectance spectra adjustment of the PS single layers can be used in the microcavity study.

\begin{tabular}{|c|c|c|c|c|c|}
\hline & \multicolumn{2}{|c|}{ Minimal thickness case } & \multicolumn{2}{|c|}{ Maximum thickness case } & $\lambda(\mathrm{nm})$ \\
\hline Thickness (nm) & $\mathrm{e}_{\mathrm{H} \min }=160.3$ & $e_{\mathrm{L} \min }=143.2$ & $\mathrm{e}_{\mathrm{H} \max }=165.4$ & $\mathrm{e}_{\mathrm{L} \min }=148.4$ & \\
\hline \multirow{2}{*}{ (As prepared) } & $\mathrm{n}_{800}=1.293$ & $\mathrm{n}_{800}=1.445$ & $\mathrm{n}_{800}=1.252$ & $\mathrm{n}_{800}=1.395$ & \multirow{2}{*}{827.4} \\
\hline & \multicolumn{2}{|c|}{$\lambda=827.4 \mathrm{~nm}$} & \multicolumn{2}{|c|}{$\lambda=827.4 \mathrm{~nm}$} & \\
\hline \multirow{2}{*}{ (Oxidation) } & $\mathrm{n}_{800}=1.198$ & $\mathrm{n}_{800}=1.39$ & $\mathrm{n}_{800}=1.243$ & $\mathrm{n}_{800}=1.339$ & \multirow{2}{*}{$795.1 \pm 1.4$} \\
\hline & \multicolumn{2}{|c|}{$\lambda=796.5 \mathrm{~nm}$} & \multicolumn{2}{|c|}{$\lambda=793.7 \mathrm{~nm}$} & \\
\hline \multirow{2}{*}{ (Silanization) } & $\mathrm{n}_{800}=1.283$ & $\mathrm{n}_{800}=1.435$ & $\mathrm{n}_{800}=1.234$ & $\mathrm{n}_{800}=1.382$ & \multirow{2}{*}{$819.5 \pm 2.2$} \\
\hline & \multicolumn{2}{|c|}{$\lambda=821.7 \mathrm{~nm}$} & \multicolumn{2}{|c|}{$\lambda=817.4 \mathrm{~nm}$} & \\
\hline \multirow{2}{*}{ (Coupling) } & $\mathrm{n}_{800}=1.320$ & $\mathrm{n}_{800}=1.485$ & $\mathrm{n}_{800}=1.27$ & $\mathrm{n}_{800}=1.427$ & \multirow{2}{*}{$844.4 \pm 2.9$} \\
\hline & \multicolumn{2}{|c|}{$\lambda=847.2 \mathrm{~nm}$} & \multicolumn{2}{|c|}{$\lambda=841.5 \mathrm{~nm}$} & \\
\hline \multirow{2}{*}{ (Grafting) } & $\mathrm{n}_{800}=1.505$ & $\mathrm{n}_{800}=1.505$ & $\mathrm{n}_{800}=1.45$ & $\mathrm{n}_{800}=1.45$ & \multirow{2}{*}{$857.0 \pm 4.1$} \\
\hline & \multicolumn{2}{|c|}{$\lambda=861.1 \mathrm{~nm}$} & \multicolumn{2}{|c|}{$\lambda=853 \mathrm{~nm}$} & \\
\hline
\end{tabular}

Table 2: List of parameters used for microcavity simulation. The resonant wavelength value and its precision are deduced for each step of the process.

Otherwise, the $\mathrm{Q}$ factors determined from experimental spectra (figures $7 \mathrm{a}$ and $8 \mathrm{a}$ ) are quite similar in every stage. The obtained values vary between 80 and 90 . These values are 
relatively low since the variation in the refractive index between the two alternating layers is not very high $(\Delta \mathrm{n} \# 0.15)$.

Comparing theoretical and experimental reflectance spectra in figure 8 for silanization and coupling steps, we can see that wavelength shifts are also in the same order: $\Delta \lambda_{\text {th }}=24.4 \pm 3.6 \mathrm{~nm}$ and $\Delta \lambda_{\exp }=23 \mathrm{~nm}$ for silanization step; for coupling step, $\Delta \lambda_{\text {th }}=24.9 \pm 5.1 \mathrm{~nm}$ and $\Delta \lambda_{\exp }=24.7 \mathrm{~nm}$. For these steps, the volume fraction of air, APTES and GL determined by reflectance spectra adjustment of the PS single layers are in the same order in the microcavity. Moreover such experimental shift values $(\Delta \lambda=19 \mathrm{~nm})$ have been obtained by Palestina and al. [9] after the silanization step for almost identical pore size.

For the grafting step (figure 8), the theoretical wavelength shift value is lower than the experimental one: $\Delta \lambda_{\text {th }}=12.7 \pm 7.0 \mathrm{~nm}$ and $\Delta \lambda_{\exp }=18.2 \mathrm{~nm}$. For the simulation, we have considered that there is a total and homogeneous infiltration throughout all the layers of the microcavity. For the small molecule sizes such as APTES and GL, we can consider that this is probably the case, but for the BSA molecules, whose size is larger, it is less likely and we could consider a gradient of BSA infiltration in the simulation microcavity spectra. However, if we take into account the precision, the experimental and theoretical results also correlate. Then, the theoretical and experimental values obtained from the single layer study are quite similar throughout the process of functionalization, meaning that the single layer results can be transposed to the microcavity study. 


\section{Conclusion}

In this paper a study of refractive index variation after each step of functionalization of POPS layers for two porosity values ( $\mathrm{L}$ and $\mathrm{H}$ ) is presented. BSA protein has been used as test molecule. Then, theoretical reflectance spectra of the layers have been calculated using the Bruggemann model. Volume fraction of the different constituents and refractive index of layers were determined after each step by adjustment of theoretical reflectance spectra with experimental ones. The specific surface of each PS layer has been deduced from the porosity and the mean pore diameter estimated by surface SEM observations. The comparison of biomolecule volume fractions calculated for $\mathrm{L}$ and $\mathrm{H}$ single layers was well correlated to the difference of their specific surface except for BSA molecules. In the L single layer, the infiltration of BSA was found to be significantly less efficient than in the $\mathrm{H}$ single layer because of small pore size.

A functionalized microcavity was prepared using the two different porosities of PS previously studied. In addition, from refractive index determined from PS layers study, a theoretical microcavity has been simulated using the matrix transfer model at each step of functionalization. The volume fractions values obtained in $\mathrm{H}$ and $\mathrm{L}$ single layer studies have been used except for the grafting step for which we took into consideration the limiting BSA infiltration condition in the overall depth of the microcavity. The comparison of theoretical and experimental microcavity reflectance spectra has revealed a good concordance of the different resonant wavelength shifts.

These results show that the method we applied in order to determine the volume fraction of different constituents is well adapted and efficient to control the functionalization process of POPS. Such a study on PS single layers will enable us to predict the functionalization of other PS optical structures such as waveguides for the development of a label-free optical biosensor with high sensitivity. 


\section{References}

[1] I. Rendina, I. Rea, L. Rotiroti, L. De Stefano, Physica E 38 (2007) 188-192.

[2] S. Ozdemir, J. and L. Gole, Current Opinion in Solid State and Materials Science 11 (2007) 92-100

[3] A. Jane, R. Drovnov, A. Hodges and N. H. Voelcker, Trends in Biotechnology vol.27, 4 (2009) 230-239.

[4] P. Rivolo, P. Pirasteh, A. Chaillou, P. Joubert, M. Kloul, J.-F. Bardeau and F. Geobaldo, Sensors and Actuators B 100 (2004) 99-102.

[5] M. Thust, M.J. Schoëning, P. Schroth, Ü . Malkoc, C.I. Dicker, A. Steffen, P. Kordos and H. Lüth, Journal of Molecular Catalysis B: Enzymatic 7_1999.77-83.

[6] H. Föll, M. Christophersen, J. Carstensen and G. Hasse, Materials Science and Engineering R 39 (2002) 93-141.

[7] G. Rong, A. Najmaie, J. E. Sipe, S. M. Weiss, Biosensors and Bioelectronics 23 (2008) $1572-1576$.

[8] S. Setzu , P. Ferrand, R. Romestain, Materials Science and Engineering B69-70 (2000) 34-42.

[9] G. Palestino, R. Legros, V. Agarwal, E. Pérez, C. Gergely, Sensors and Actuators B 135 (2008) 27-34.

[10] H. Ouyang, C. C. Striemer, and P. M. Fauchet, Applied Physics Letters 88, (2006) $1631081-3$.

[11] V. Torres-Costa, F. Agullo-Rueda, R.J. Martin-Palma and J.M. Martinez-Duart, Optical Materials 27 (2005) 1084-1087.

[12] F. Geobaldo, P. Rivoloa, P. Ugliengo, E. Garrone, Sensors and Actuators B 100 (2004) $29-32$.

[13] E. J. Anglin, L. Cheng, W. R. Freeman, M. J. Sailor, Advanced Drug Delivery Reviews 60 (2008) 1266-1277. 
[14] H. Ouyang,_C. C. Striemer, and P. M. Fauchet, Applied Physics Letters 88, (2006) $1631081-3$.

[15] F. Cui, Y. Cui, H. Luo, X. Yao, J. Fan and Y. Lu, Chinese Science Bulletin, vol.511, $\mathrm{n}^{\circ} 18$ (2006) 2201-2207.

[16] S.B. Adeloju and A.T. Lawal, Analytica Chimica Acta, 691 (2011) 89-94.

[17] D. S. Bethune, J. Opt. Soc. Am. B, Vol. 6, 5 (1989) 910-916.

[18] Handbook of chemistry and physics, $78^{\text {th }}$ ed.. ; Lide, D.R., Ed.; CRC Press : Boca Raton, FL, 1997.

[19] http://www.sigmaaldrich.com.

[20] D.E. Aspnes, Thin Solid Films, 89 (1982) 249.

[21] K. Baral, R. Herino, G. Bomchil, J. Appl. Phys., 59 (2) (1986) 439.

[22] E. V. Astrova, V. B. Voronkov, A. D. Remenyuk, and V. B. Shuman, Semiconductors, 33, (1999) 1149-1155.

[23] H. Ouyang and P. M. Fauchet, SPIE Optics East 2005.

[24] M. Lee and P. M. Fauchet, 15, No. 8, Optics express (2007) 4530.

[25] K. Nakamura, K. Matsumoto, Journal of Membrane Science 145 (1998) 119-128.

[26] J. Charrier and M. Dribek, J. App. Phys., 107 (2010) 044905-1. 